\title{
La CRÓNICA DE FERNANDO IV EN EL SIGLO XVI: UNA COMPILACIÓN INÉDITA DE Pedro Barrantes Maldonado
}

\author{
CARMEn Benítez Guerrero² \\ Universidad de Sevilla
}

Recibido: 9 de junio de 2019

Aceptado: 25 de junio de 2019

\section{Resumen}

El manuscrito II/2457 del Palacio Real de Madrid conserva la compilación de una Crónica de Fernando IV que permanece prácticamente desconocida hasta la fecha aunque su encabezamiento dice que fue realizada por Pedro Barrantes Maldonado. Este trabajo pretende llamar la atención sobre la obra, ofrecer una breve presentación tanto del testimonio, como del texto que transmite, y acercarse a las principales diferencias que éste presenta con respecto a su homónima medieval. En este sentido, y para terminar, resultará esencial valorar su relación con los testimonios manuscritos que conocemos de la crónica medieval, lo que permitirá arrojar nuevas pistas acerca de la problemática historia textual de ésta última.

\section{Palabras clave}

Crónica de Fernando IV, Pedro Barrantes Maldonado, historiografía, tradición manuscrita, crítica textual.

\begin{abstract}
The manuscript II/2457, preserved in the Royal Palace's library in Madrid provides the compilation of a chronicle of Fernando IV that remains practically unknown so far, although it can be attributed to Pedro Barrantes Maldonado. In this article, I intend to draw attention to this work, presenting a brief description of both the manuscript and the text, and highlighting its main differences with the medieval version. Lastly, I focus on the relationship between Barrantes' manuscript and the medieval manuscripts of the chronicle in order to come up with new clues about its textual history.
\end{abstract}

\section{Keywords}

Chronicle of Fernando IV, Pedro Barrantes Maldonado, Castilian historiography, manuscript tradition, textual criticism.

\footnotetext{
Este trabajo se realiza gracias a un Contrato de Acceso al Sistema Español de Ciencia, Tecnología e Innovación del V Plan Propio de Investigación de la Universidad de Sevilla. Una aproximación inicial al códice analizado se presentó en el XVI Congreso Internacional de la AHLM celebrado en Oporto en 2015. Agradezco a Carmen del Camino, Emma Falque, Ricardo Pichel, Pablo Toribio y Covadonga Valdaliso su ayuda en la elaboración de este trabajo.

2 Dpto. Historia Medieval y Ciencias y Técnicas Historiográficas. Universidad de Sevilla. Correo electrónico: cbenitez@us.es. ORCID: https://orcid.org/0000-0001-9610-9024.
} 


\section{Résumé}

Le manuscrit II/2457 de la Bibliothèque du Palais Royal de Madrid conserve la compilation d'une Chronique de Ferdinand IV pratiquement inconnue jusqu'à ce jour, même si son intitulé affirme qu'elle fut composée par Pedro Barrantes Maldonado. Cet article vise à attirer l'attention sur cette œuvre, à présenter brièvement le codex et le texte qu'il contient, et à inventorier les principales variantes existant entre ce témoignage et l'original médiéval. Pour finir, on tentera de préciser quels rapports cette version entretient avec les témoignages manuscrits que l'on conserve de cette chronique, ce qui ouvrira de nouvelles pistes dans l'approche de son histoire textuelle qui reste problématique.

\section{Mots-clés}

Chronique de Ferdinand IV, Pedro Barrantes Maldonado, historiographie médiévale, tradition manuscrite, critique textuelle.

El análisis de la tradición manuscrita de la Crónica de tres reyes desarrollado en los últimos años ha traído consigo el reconocimiento de algunos testimonios que ejemplifican la recepción y reelaboración que ésta tuvo en el siglo XVI, dentro de un contexto general de reescritura de la historia de España. Es el caso, por ejemplo, del manuscrito 84-7-34 de la Biblioteca Colombina de Sevilla que hoy se sabe realizado por la mano de Florián Ocampo, o del texto transmitido por el MSS/1342 de la Biblioteca Nacional de España que ha resultado ser parte de la ingente labor historiográfica del arcediano de Ronda, Lorenzo de Padilla ${ }^{3}$. A estos avances debe sumarse el estudio del manuscrito conservado en el fondo de la Biblioteca del Palacio Real de Madrid con la signatura II/2457 y que presenta una reelaboración de la Crónica de Fernando IV realizada por el historiador extremeño Pedro Barrantes Maldonado. El encabezamiento que abre la obra indica:

Cronica del rey don Fernando Quarto deste nombre en la casa de Castilla que llamaron el Emplaçado que gano a los moros la ciudad de Gibraltar y la de Alcaudete hijo del rey don Sancho el Brauo y de la reina donna Maria, conpilada por Pero Barrantes Maldonado ${ }^{4}$.

El testimonio en cuestión parece haber pasado prácticamente desapercibido ${ }^{5}$, a pesar de que se encuentra perfectamente catalogado en el fondo de la mencionada biblioteca ${ }^{6}$ y asimismo recogido en el inventario de los libros del conde de Gondomar realizado

\footnotetext{
3 Saracino, "Sánchez de Valladolid en el siglo XVI"; Saracino, Lorenzo de Padilla: un prosista anónimo del siglo XVI; SARACINo, "La primera parte de las Crónicas de España de Lorenzo de Padilla".

4 Madrid, Biblioteca del Palacio Real, II/2457, f. 1r. Se transcribe actualizando simplemente la separación de palabras y las mayústulas y minúsculas.

5 La existencia de esta obra y su falta de estudio fue ya subrayada en BENítez, "Manuscritos y cronistas", p. 79 y Benítez, Crónica de Fernando IV, p. LXXVII.

6 IBIS. Base de datos del patrimonio bibliográfico de Patrimonio Nacional, http://realbiblioteca.patrimonio nacional.es/cgi-bin/koha/opac-main.pl.
} 
en 1623 y publicado en 1903 por Manuel Serrano y Sanz . No aparece sin embargo en la inmensa obra de Nicolás Antonio de $1672^{\circ}$, en el catálogo realizado por Vicente Barrantes en $1863^{\circ}$, en el estudio de Pascual de Gayangos para su edición de las Ilustraciones de la Casa de Niebla ${ }^{10}$, en el Diccionario de extremeños ilustres realizado en $1884^{11}$, en la ingente recopilación bibliográfica realizada por Simón Díaz ya en el siglo $\mathrm{XX}^{12}$, en el catálogo bibliográfico recientemente realizado por el grupo de investigación "Barrantes-Moñino" ${ }_{13}$, o en la completa base de datos de Philobiblon ${ }^{14}$. Por el contrario, sí que recogía la mención a esta obra Casto María del Rivero en el trabajo que dedicó a la Crónica de tres reyes en $1942^{15}$, y asimismo se mencionaba sin llamar la atención sobre ella en la biografía de Pedro Barrantes Maldonado publicada por Juan Francisco Maura para el Diccionario Biográfico de la Real Academia de la Historia ${ }^{16}$ y en la reciente obra dedicada a las Noticias de Alcántara publicada por la Diputación de Cáceres en $2010^{17}$.

En consecuencia, puede afirmarse que su crónica permanece a día de hoy prácticamente desconocida, carente de estudio y su texto todavía inédito. A continuación presentaré, en primer lugar, una descripción del único manuscrito conocido del texto, el mencionado II/2457 de la Biblioteca del Palacio Real de Madrid. Después me ocuparé de la Crónica de Fernando Quarto compilada por Pedro Barrantes. Concretamente, tras un rápido recorrido por la faceta literaria del autor, me detendré en la búsqueda de una posible cronología de elaboración del texto. Después me centraré en el análisis comparativo del texto de Barrantes con la crónica medieval que le sirve de fuente, tanto desde el punto de vista de la estructura del texto, como del contenido, y en este

\footnotetext{
7 "Índiçe y inventario de los libros que ay en la librería de Don Diego Sarmiento de Acuña, Conde de Gondomar, en su casa de Valladolid, hecho a último de abril de 1623", Madrid, Biblioteca Nacional de España, MSS/13593 y MSS/13594. La mención a la Crónica de Fernando IV de Barrantes Maldonado se encuentra dentro del listado de Libros manuscritos o de mano del segundo volumen: "Pedro Barrantes Maldonado. Chronica del Rey don Fernando el 4. . F.", MSS/13594, f. 164r. El inventario fue publicado en partes por Manuel Serrano y Sanz en la Revista de archivos, bibliotecas y museos, donde se puede consultar el manuscrito que nos ocupa en Serrano y SAnz, "III. Libros manuscritos o de mano de la Biblioteca del Conde de Gondomar", p. 66.

8 Nicolás Antonio, Bibliotheca Hispana sive Hispanorum, t. 2, p. 174.

9 Barrantes, Catálogo razonado y crítico de los libros, memorias y papeles, pp. 4-10.

10 Gayangos, "Introducción", pp. v-vi.

11 DíAz y PÉRez, Diccionario histórico, t. 1, pp. 78-80.

12 Díaz, Bibliografía de la literatura hispánica, t. 6, pp. 323-325; adiciones al t. 5-6, p. 205.

13 Cañas y Tejeiro (eds.), Catálogo bibliográfico de estritores extremeños anteriores a 1750, t. 1, pp. 251-254.

14 Faulhaber et. al. (dirs.), BETA, http://vm136.lib.berkeley.edu/BANC/philobiblon/betaen.html.

15 Rivero, "Índice de las personas, lugares y cosas notables que se mencionan en las tres crónicas", p. 574 , en nota.

16 “(....) escribió también la Crónica del rey don Fernando quarto deste nombre en la casa de Castilla, que llamaron El Emplaçado, que ganó a los moros la ciudad de Gibraltar y las de Alcaudete (...) cuyo manuscrito se conserva en el Palacio Real de Madrid (Real Biblioteca, II/2457)", MAURA, "Pedro Barrantes Maldonado", http://dbe.rah.es/.

17 Martín et al., Noticias de Alcántara, t. 1, p. 96.
} 
sentido, de su relación con los testimonios manuscritos conservados. Esto permitirá volver sobre algunas de las principales problemáticas del texto medieval ${ }^{18}$.

\section{El manuscrito II/2457 de la Biblioteca Real de Palacio (Madrid)}

El II/2457 es un códice en formato folio copiado a línea tirada. Contiene 57 folios y dos hojas de guarda que cuentan con tres sistemas de numeración diferentes. En primer lugar, una foliación moderna en números arábigos realizada a lápiz y localizada en el margen superior derecho. La encontramos entre los folios 1 a 57, con un folio sin numerar entre el 41 y el 42, y saltándose el 56, de ahí que alcance 57 en la numeración ${ }^{19}$. La segunda foliación se realiza en números romanos y aparece en el margen inferior derecho del recto a partir del folio 44, comenzando en "ii" ${ }^{20}$. Posiblemente esta numeración se iniciase en el folio 43, coincidiendo con el cambio de letra que en seguida comentaré, pero se ha perdido a causa del guillotinado ${ }^{21}$. Una tercera foliación, también en numeración romana, se halla en el margen inferior izquierdo del vuelto, resultando invisible en algunos folios ${ }^{22}$, pero resulta coincidente con la arábiga cuando ésta aparece, por ejemplo, en el folio 2. Parece la foliación original del códice, ya que presenta el mismo tono que la tinta del cuerpo de texto. Cabe decir que las dos foliaciones en numeración romana han sido realizadas por manos distintas.

Desde el punto de vista material, el conjunto presenta una factura unitaria, aunque la colación es difícil de determinar por su irregularidad y la falta de reclamos. Está realizado en papel cuya filigrana muestra una mano abierta de la que sale una estrella de cinco puntas con flor de lis en el puño ${ }^{23}$. Ésta podría situar la fabricación del papel en la primera mitad del siglo $\mathrm{XVI}^{24}$.

\footnotetext{
18 Para agilizar las referencias comparadas en adelante se citará la Crónica de Fernando $I V$ realizada por Barrantes Maldonado con la signatura del manuscrito y el número de folio (II/2457, f. 0r), el texto medieval de la Crónica de Fernando $I V$ de manera abreviada a través de la edición de Benítez, Crónica de Fernando IV, indicando capítulo y segmento (CFIV, § X.0) y el texto de las Ilustraciones a través de la edición de Gayangos en el Memorial histórico español, indicanto volumen y página (BARRANTES, Ilustraciones, t. 9, p. 0).

19 La distribución sería la siguiente: 1 (guarda) $+57(1-41+[1]+42-57)+1$ (guarda).

20 Aparece doblemente, una de las veces tachado.

21 También presenta otros problemas: la numeración en el folio VIII aparece cortada (f. 50); a veces se transparenta en el vuelto dando la impresión de que hay otra foliación, y tampoco aparecen, posiblemente por guillotinado del folio, el X y XI (ff. 52 y 53), ni tampoco hay cifra en los ff. 55 y ss.

22 No aparece en el folio 1, posiblemente por rotura, ni desde los folios 30 a 43, y está cortada en [X] XIX.

${ }^{23}$ La filigrana resulta homogénea en todo el manuscrito, bien se encuentre mirando hacia arriba o hacia abajo; por ejemplo, ff. 1, 17, 28, 33, 40, 43, 52 .

24 No se identifica exactamente con ninguna recogida en el catálogo de Briquet, aunque las más similares se sitúan en las primeras décadas del siglo XVI; por ejemplo, Briquet, Les filigranes, t. 3, n. 11187. El motivo parece ser común en este contexto, como se afirma asimismo en estudios exhaustivos realizados en archivos locales, Córdoba y Cerezo, "Filigranas del archivo municipal de Córdoba", p. 407.
} 
A pesar de esta homogeneidad formal desde el punto de vista material se distinguen varias manos, todas ellas del siglo XVI, que se alternan sin un orden aparentemente claro. La primera abarca los folios 1 a 43r y vuelve a aparecer puntualmente en algunos fragmentos de los folios 45v, 46r-47r y 52r-v. Muestra las características de una llamada redondilla procesal más o menos cursiva a lo largo de la copia y elementos mixtos que aúnan la tradición gótica con la humanística. A veces presenta un estilo extremadamente caligráfico que no obstante creo que podemos seguir considerando la misma mano, como ocurre en el folio $3 \mathrm{v}$. La segunda empieza a aparecer en el folio 43r y llega, con las excepciones antes aludidas, hasta el folio 55r. Muestra también una hibridación, si bien aquí la tradición cortesana presenta ya una marcada inclinación a la derecha e incorpora en mayor medida elementos de la letra humanística. Podría establecerse un tercer tipo de letra, mucho más caligráfica, que aparece puntualmente en el folio 23r; brevemente, en apenas las dos líneas iniciales, en el folio 24r; e incluso en medio de una línea abarcando apenas unas palabras en el folio 32r. Esta mano quizás podría pensarse cercana a la que había realizado parte del folio $3 \mathrm{v}$.

La alternancia de manos no tiene una explicación aparente, pues salvo en el caso del folio $3 \mathrm{v}$, en el que esta mano menos cursiva copia parcialmente un texto en latín, en el resto de los casos no se observa una fractura en el texto o un cambio de fuente o de lengua. Por otra parte, podría dudarse del número de personas que verdaderamente están realizando la copia. En efecto, los casos en los que la primera mano aparece de modo menos cursivo llegan a confundirse con la mano tres cuando ésta presenta rasgos de una letra cursiva, y del mismo modo ocurre con la mano dos, ciertamente cercana a la primera de ellas cuando la escritura es más cursiva. Por lo tanto, resulta difícil deducir hasta qué punto las divergencias son resultado de la implicación de distintas personas o de distintos estilos adoptados por una misma mano. En todo caso, las manos que aparecen en el manuscrito, y esta realidad alternante, resultan muy similares a las que se observan en otros códices atribuidos a Barrantes Maldonado. Esto puede considerarse un indicio de que el manuscrito se relaciona con su entorno próximo. También se observa en otros testimonios la mano que realiza los textos latinos que en seguida comentaré, copiados en una bastarda española propia de la tradición humanística ${ }^{25}$.

\footnotetext{
25 Véase, por ejemplo, la Crónica de Enrique III de la Real Academia de la Historia, coleccción San Román, Signatura: 2/Ms. 42. Allí puede observarse perfectamente la que hemos considerado primera mano copiando el cuerpo del texto, mientras que la que copia los epígrafes de capítulo resulta idéntica a la bastarda que aquí aparece copiando dos textos latinos finales. Esta copia se considera un autógrafo de Barrantes, y está sin duda realizada a limpio, en dos columnas. Compruébese también el MSS/1663 de la Biblioteca Nacional de España, donde aparece una mano muy similar a la primera de las comentadas en la sección correspondiente a la Crónica de Enrique III. El manuscrito MSS/6119 de la misma biblioteca presenta asimismo la mano primera, con menor a mayor grado de letra cursiva según avanza la copia, y también la segunda mano, por ejemplo en folios 19r-20r. La alternancia de las dos puede observarse perfectamente en el folio $27 \mathrm{v}$. Igualmente la primera mano es similar a la que copia el códice autógrafo que sirvió de base a la edición de las Ilustraciones realizada por Gayangos, el 9/134 de la Real Academia de la Historia.
} 
En general, el códice presenta un buen estado de conservación, solo con manchas de tinta puntuales que no dificultan la lectura. Se observa no obstante corrosión por la oxidación de la tinta, por ejemplo, en el folio 44, y una rotura en la esquina superior derecha de varios folios que no ha supuesto pérdida de texto o foliación (sin duda la foliación moderna que tiene esta localización es posterior a la rotura). Sí ha sido guillotinado el final de las letras del margen derecho en el recto de los folios a partir del 43 y falta parte de la foliación antigua posiblemente por el guillotinado realizado para la nueva encuadernación.

La encuadernación es posterior. Está realizada en pasta valenciana jaspeada con una sencilla rueda dorada que bordea las cubiertas de 296x220mm. En el lomo aparece un tejuelo superior en rojo donde se lee «CRON. DE FERN. 4.» junto a decoración con florecillas, mientras que el interior presenta papel marmoleado o jaspeado al baño. La biblioteca la atribuye a Santiago Martín Sanz, encuadernador del Palacio Real del reinado de Fernando VII cuyo taller se localizó en el Juego de Pelota ${ }^{26}$.

Como se indicó anteriormente, el manuscrito estuvo entre los libros de la biblioteca del conde de Gondomar, de lo cual queda constancia no sólo en el inventario que se realizó en 1623 , sino en la signatura Sal. $2^{\mathrm{a}}$ est. 10 cax. $7^{\circ}$ que aparece en el margen superior del folio 1r. En el inventario en cuestión se da cuenta de los libros que estuvieron en la biblioteca del conde en su casa de Valladolid, por lo que allí se encontraría este manuscrito ${ }^{27}$, pasando a formar parte de la Biblioteca Real a principios del siglo XIX, durante el reinado de Carlos IV.

El texto principal del códice es la Crónica de Fernando Quarto compilada por Pedro Barrantes Maldonado, que abarca los folios 1r a 55r. El título se incorpora al inicio del folio $1 \mathrm{r}$ sin decoración, más allá de la utilización de un módulo mayor en las primeras palabras del título y del texto del primer capítulo. La crónica se abre con el incipit "como fue enterrado el rey don Sancho en la çiudad de Toledo" y se cierra con un explicit consistente en una nota final en la que el autor afirma que "esto que yo digo es lo mas zierto aunque escrivo lo que dizen los coronistas" ${ }^{28}$. No existe una caja de escritura regular ni pautado, por lo que el número de líneas varía notablemente entre unos folios y otros, sobre todo si tenemos en cuenta la alternancia de tipos de letra ${ }^{29}$.

Al margen de la crónica, son extremadamente interesantes las pruebas de escritura y anotaciones de los dos últimos folios del códice, que sin duda permiten notar el contexto humanista del autor. En el folio 55v se observan tres textos en latín, el primero de ellos

\footnotetext{
26 Una descripción más detallada del mismo puede encontrarse en el catálogo de la biblioteca, IBIS. Base de datos del patrimonio bibliográfico de Patrimonio Nacional, http://realbiblioteca.patrimonio nacional. es/cgi-bin/koha/opac-main.pl.

27 Madrid, Biblioteca Nacional de España, MSS/13593, f. 1r.

28 Madrid, Biblioteca del Palacio Real, II/2457, ff. 1r y 55r respectivamente.

29 Por ejemplo, 34+1 (línea en blanco), f. 11r; o 39+2 en blanco en f. 18r; 34 en f. 36r; o 32 en f. 52r y $31+1$ en f. $53 \mathrm{r}$. Los folios pueden presentar además medidas dispares; por ejemplo, 291x207mm en ff. 1 , $6,11,13 ; 291 \times 204 \mathrm{~mm}$. en f. 18 o $302 \times 203 \mathrm{~mm}$. en f. 36 .
} 
en módulo mayor y letra más cursiva; los dos restantes, como se indicó líneas arriba, en una bastarda española propia de la tradición humanística.

El primero es un fragmento dedicado a la fortuna que, a tenor de la nota final -"Grece multo iucundius et salsius"-, resulta de una traducción del griego:

"Fortuna / incusant me mortales et iniquam vocant / quod opes, diuitias, et alia indignis tribuam / atque non est meum dare sed fratris fati / cunctorum dispensator. Venio enim ad portas / urbium, rogo: cui sit bene? dicunt Lucullo / Crassoque frater dedisse, addo et ego his etiam / rogo etiam cui sit male? dicunt Crispo, Cethego / addo et etiam his ego. itaque mortales simile de me queri" ${ }^{30}$.

El segundo es parte de un epigrama de Marcial dedicado a Quintiliano ${ }^{31}$, que va glosado con una sentencia marginal en castellano, en letra diferente, muy cursiva y acaso posterior. La sentencia dice: "Al tiempo pasado el tiempo venido lo pone en olvido"; y el epigrama:

"Quintiliane, vagae moderator summe iuuente, / gloria Romane Quintiliane togae. / Viuere quod propero pauper et inutilis annis / Da ueniam, properat viuere nemo satis" ${ }^{\prime 32}$.

El tercero y último es la traducción latina de un epigrama de Calímaco que parece relativamente común en los ambientes humanistas del contexto de Barrantes ${ }^{33}$ :

Vita uale, muro praeceps dilapsus ab alto, / dixisti moriens Ambrathiota puer. / Nullum in morte malum credens, sed dicta Platonis / non ita erant animo percipienda tuo ${ }^{34}$.

En los comentarios a la Ciudad de Dios de San Agustín que Luis Vives realizó en 1522, reproducía esta traducción latina afirmando que recordaba haberlo leído en latín ${ }^{35}$, pero sin aportar la procedencia de la traducción. Aparecía allí con la variante scripta por

\footnotetext{
30 Madrid, Biblioteca del Palacio Real, II/2457, f. 56v.

31 Marcial, Epigramas, 2004, II, 90, p. 91. Nótese que el texto de Marcial dice nec inutilis y no et inutilis. Sobre la amplia recepción que Marcial tuvo en España y Europa en el siglo XVI véase MarciaL, Epigramas, 1997, pp. 71 y ss.; MARCial, Epigramas, 2004, pp. XLII y ss. y GiL, "Marcial en España”. 32 Madrid, Biblioteca del Palacio Real, II/2457, f. 56v.

33 Calímaco, Himnos, epigramas y fragmentos, Epigramas, 23, pp. 103-104. En él, Cleombroto el Ambraciota se suicida tras leer el Fedón de Platón.

34 Madrid, Biblioteca del Palacio Real, II/2457, f. 56v.

35 "Latinum memini me legere", VIVEs, Diui Aurelii Augustini, f. 13v.
} 
dicta, al igual que ocurre en la obra de Alfonso de Castro de $1547^{36}$. La que presentan estas obras, y el manuscrito de Barrantes, parece ser por lo tanto una traducción libre del epigrama, que se aleja notablemente de otras traducciones latinas más o menos cercanas en el tiempo. Pero desconocemos, como Luis Vives, la procedencia de la misma ${ }^{37}$. Para finalizar la descripción del códice y de sus contenidos debo detenerme en las pruebas de escritura que plagan el folio $57 \mathrm{v}$. No en todos los casos son fáciles de descifrar, pero pueden reconocerse algunas menciones interesantes. Por el momento, pasaré a describirlas.

En una letra cursiva y escritas en el sentido natural del folio se lee la fórmula epistolar "Tuus vere et ex animo", así como los nombres "Joan Lopez" y "Diego" 38 . En dirección inversa a la posición natural del folio, y en letra humanística quizás semejable a la que anotaba los dos epigramas finales, se leen varias anotaciones entremezcladas ${ }^{39}$ :

"Caminando por mis males por la muy famosa y nombrada çiudad de Granada | el muy ¿? Ilustre y Reuerendissimo señor | don Antonio Manrrique arçobispo $\mid$ \{coronica del rey don Alonso el casto\} de Mantua sale el marques de Guandiante | mandamiento muy riguroso y de grand crueldad | coronica del marques de Mantua | Yo mando que ninguno hombre sea osado | a mantener y substentar hermosuras y gentilezas $\mid i$ ? como su tienpo de don Aluaro $\{$ de cada mes\} || Domingo de Miramon"40.

También en esta dirección inversa a la posición del folio, pero en letra que va cambiando desde una más o menos similar a la anterior hasta otra que podría identificarse con la que hizo la anotación junto al texto de Marcial, se lee:

"Domingo de Eguino gentil hombre de su magestad | Domingo de Eguino gentil hombre de la voca de su | magestad y del su consejo y comisario general en la $\mid$ su corte y en todos sus reinos y senorios $\mid$ conforme al mandami ${ }^{\circ}$ de su magestad".

\footnotetext{
36 Castro, De iusta haereticorum, f. 350v.

37 Por ejemplo, aunque ya de 1577, Callimachi Cyrenaei hymni, n. 29, p. 70. Sobre el epigrama y algunas noticias acerca de su recepción véase CALÍmaCo, Himnos, epigramas y fragmentos, pp. 19 y ss.; FIORENTINI, "Lector indoctus. Callimaco e Cicerone" y Garulli, "Cleombroto de Ambracia", especialmente nota 5.

38 Se observan otras anotaciones ilegibles, una de las cuales quizás diga "contra verba". Similar a esta letra, pero en sentido vertical, se lee posiblemente "fran".

39 Se desarrollan las abreviaturas. Utilizo | para indicar los saltos de línea; || cuando hay varios saltos de línea; y \{\} para separar distintos textos en la misma línea. Se pone en cursiva una anotación que parece letra diferente.

40 En sentido vertical a la dirección natural del folio se leen dos anotaciones en una letra similar a ésta; una resulta ilegible, la otra dice "yo mando".
} 
Como se observa, las pruebas de escritura son de contenido variado. Junto a los nombres y referencias a textos diversos, destacan los fragmentos poéticos. En este sentido se identifica el primer verso del romance de García Sánchez de Bajadoz, "caminando por mis males", así como el primero del romance anónimo en el que el Marqués de Mantua se encontraba con su sobrino Valdovinos, "de Mantua sale el Marqués"

\section{Una contextualización: el autor y su extensa obra}

Pedro Barrantes Maldonado fue un gran conocedor de su época ${ }^{42}$, como se desprende de los materiales de trabajo que empleó a lo largo de su producción historiográfica. A ellos tuvo acceso en sus viajes por Europa, en los que se ocupó de recopilar y traducir textos; y también cuando trabajó en la casa del duque de Medina Sidonia. Muy posiblemente formó una importante biblioteca cuando finalmente estableció su residencia estable en Alburquerque y luego en Alcántara, después de volver de Sanlúcar de Barrameda ${ }^{43}$.

En el prólogo a las Ilustraciones de la casa de Niebla habla de sus viajes por Francia, Flandes o Alemania, que comenzaron en 1532, y dice haber hallado "libros en diversas lenguas". Estos le ayudaron a escribir sobre "los linages y hechos de algunos reyes y principes, ansi naturales como estrangeros", y entretanto también tradujo "en nuestra lengua las cosas de los turcos, y de la francesa los annales y coronicas de Francia" ${ }^{4}$. Este bagaje europeo creció durante su estancia en la casa del duque de Medina Sidonia, esto es, a partir de 1540, donde afirma haber visto "los privilegios, testamentos, cartas de doctos, y finalmente todas las escrituras y memoriales antiguos y modernos de la Casa de Niebla"45. De ellos volcó en su obra sobre los Guzmanes diversas fuen-

41 Para el primero véase Romancero general, t. 1, p. LXVIII y t. 2, n. 1876, p. 640. También Cancionero general, f. CXXXVIIv. Para el segundo véase Romancero general, t. 1, LXVII y n. 355, p. 207, con la variante salio por sale.

42 Sobre el autor, cuya actividad parece estar aún poco analizada, pueden verse Devís, "Presentación”, pp. XXI-XXVI; Barrantes, Ilustraciones de la casa de Niebla, t. 9, pp. iv-v y t. 10, pp. 471-535; CARABIAS, "Turcos contra católicos", pp. 4-7; CARABiAs, "Pedro Barrantes Maldonado", pp. 215-218; DíAz y Pérez, Diccionario histórico, t. 1, pp. 78-79; CAÑAS y TEJEIRO (eds.), Catálogo bibliográfico de estritores extremeños anteriores a 1750, t. 1, p. 251; MAURA, "Pedro Barrantes Maldonado", http://dbe.rah.es/; SÁNCHEZ Alonso, Historia de la historiografía, pp. 377-378; MARTín et al., Noticias de Alcántara, t. 1, pp. $25-72$.

43 Esto sucedió en 1544 y hacia 1550 respectivamente, si tenemos en cuenta la información extractada por Pascual de Gayangos de las memorias de Barrantes que Fabián Antonio de la Cabrera y Barrantes copió en 1705, según afirma, a partir de papeles originales, BARRANTES, Ilustraciones, t. 10, p. 480. La información sobre el manuscrito de Fabián Antonio en BARrantes, Ilustraciones, t. 10, pp. 471 y 472 . Se trata del MSS/17996 de la Biblioteca Nacional de España. Ana María Carabias considera a Barrantes en Alburquerque desde 1541 y en Alcántara desde 1549, CARABias, "Pedro Barrantes Maldonado", p. 215.

44 Barrantes, Ilustraciones, t. 9, p. 3. Entre las obras manuscritas de Pedro Barrantes Maldonado, Nicolás Díaz y Pérez recoge en 1884 una "Recopilación de todas las crónicas de Francia”, DíAz Y PÉREZ, Diccionario histórico, t. 1, p. 79. Esta aparece entre las obras perdidas de Barrantes en CAÑAS y TEJEIRO (eds.), Catálogo bibliográfico de escritores extremeños anteriores a 1750, t. 1, p. 253. De la traducción de "los anales de todas las coronicas de Francia hasta el rey Francisco" en su segunda visita a Francia se da cuenta en sus memorias, CABrera, Noticias de los papeles de don Pedro Barrantes Maldonado, f. 60r. 45 Barrantes, Ilustraciones, t. 9, p. 7. 
tes documentales e historiográficas de singular importancia ${ }^{46}$, las cuales sin duda le aportaron un profundo conocimiento acerca del reinado de Fernando IV, en el que se inscribía parte de la trayectoria de Alfonso Pérez de Guzmán y de su hijo. Muchas de estas fuentes entraron en el texto que analizamos de manera indirecta, pues como en seguida comentaré, las Ilustraciones fueron también una de sus fuentes.

Incluso cuando se asentó en Alburquerque y Alcántara siguió estando directamente informado de los acontecimientos externos, como demuestra la colección de cartas que intercambió con diversos personajes implicados en la política imperial. Así ocurre con las cartas que intercambia con Bernardo de Aldana, su sobrino, desde Alemania, Austria o Hungría ${ }^{47}$, de las que Fabián Antonio de la Cabrera afirmaba haber visto «las cartas originales que tiene cosidas en un legajo el dicho Pedro Barrantes Maldonado $\rangle^{48}$. Como luego comentaré, en ellas Pedro Barrantes solicitaba a sus parientes información sobre la situación en Europa.

Conviene también mencionar su vasta producción literaria. Además de las traducciones, entre las que se cuentan no sólo las de crónicas francesas, sino el Commentario delle cose de' Turchi de Paulo Jovio que tradujo del italiano ${ }^{49}$, Barrantes Maldonado compuso varias obras, algunas de ellas hoy perdidas ${ }^{50}$. Se acercó al género del diálogo en su obra dedicada al Saco de Gibraltar de $1540^{51}$, así como al género poético en las "trobas" que hizo en Alemania ${ }^{52}$. Pero sin duda la faceta más desarrollada por Barrantes Maldonado fue la historiográfica. Entre las obras conservadas pueden mencionarse su Crónica de Enrique III, una Historia de los condes de Flandes y emperadores de Alemania, los Apuntamientos breves para la historia de Barrantes, Maldonados y Aldanas y otros linajes de Extremadura, las conocidas como Antigüedades de la villa

\footnotetext{
46 Carriazo, "La Crónica de San Isidoro del Campo".

47 Barrantes, Ilustraciones, t. 10, pp. 487 y ss.

48 Cabrera, Noticias de los papeles de don Pedro Barrantes Maldonado, f. 26r.

49 "El discursso que Paulo Jovio compusso de la generación de los turcos y lo dio de su mano al emperador Carlos $5^{\circ}$ en la ciudad de Viena en Austria el año de 1532", CABrera, Noticias de los papeles de don Pedro Barrantes Maldonado, f. 60r.

50 "Escribió más de 40 obras, entre las compuestas y las traducidas, de las que sólo se conserva siquiera una cuarta parte", MARTín et al., Noticias de Alcántara, t. 1, p. 25. De manera general, véase al respecto Barrantes, Ilustraciones, t. 9, pp. V-VI; DíAZ y PÉrez, Diccionario histórico, t. 1, pp. 79-80; CAÑAS y Tejeiro (eds.), Catálogo bibliográfico de estritores extremeños anteriores a 1750, t. 1, pp. 251-254; CABrera, Noticias de los papeles de don Pedro Barrantes Maldonado, ff 60r-v; Martín et al., Noticias de Alcántara, t. 1, pp. 85-99.

51 En ocasiones esta obra aparece listada dividida en dos, el Diálogo del saco de Gibraltar y la Declaración de lo que hizo la armada turquesa desqeu salió de Gibraltar, CAÑas y TeJeIRo (eds.), Catálogo bibliográfico de estritores extremeños anteriores a 1750, t. 1, p. 252. Sin embargo, son dos partes de una misma obra, la primera dedicada al ataque de los turcos y la segunda al contrataque español, CARABIAS, "Turcos contra católicos", pp. 3-4. A ella se refiere Barrantes como "un libro que llamo Dialogo de Pedro Barrantes Maldonado", del que aclara que "anda ympresso de molde", CABrerA, Noticias de los papeles de don Pedro Barrantes Maldonado, f. 60v.

52 "Las trobas siguientes hizo Pedro Barrantes Maldonado estando en Alemaña en la guerra del turco en loor de los españoles con vn romance en que se recuenta la supita y muy valerosa partida del yllustrissimo señor duque de Bejar a la mesma guerra", Madrid, Biblioteca Nacional de España, R-9420.
} 
de Alcántara ${ }^{53}$ y su obra más conocida, las Ilustraciones de la casa de Niebla ${ }^{54}$. Entre las que se consideran perdidas están una Recopilación de las crónicas de Francia de Carlomagno a Francisco I, el Libro de las cosas más notables acaecidas en la cristiandad ${ }^{55}$, una Noticia genealógica de los Barrantes de Alcántara continuada por Rodrigo Barrantes y Moscoso, arcipreste de Valencia de Alcántara ${ }^{56}$ y las Corónicas de España de Alfonso X a la toma de Granada, también conocida como La Maldonada. Las memorias de Barrantes Maldonado extractadas por Fabián Antonio de la Cabrera dicen de ella:

"Recopilo las coronicas de España en vn volumen por espacio de quatrocientos y quarenta años desde el tiempo del rey don Alonsso el desimo electo emperador de Roma hasta ser ganada la siudad de Granada de los moros y llamo esta coronica La Maldonada para la qual pidio preuillejio al rey don Felipe para ymprimirla, y cometio el conssejo ¿?tal doctor Castro que la viese y viola y aprobola y esta mandada ymprimir $\rangle^{57}$.

Pero a pesar de ello, no hay rastro impreso ni manuscrito de la obra ${ }^{58}$. Díaz y Pérez afirma todavía en 1884 que "los Ms. de estas obras existen en la B. N."” estaba ya ilocalizable a mediados del siglo $\mathrm{XX}^{60}$. Existe no obstante otra información que viene a poner dudas sobre el asunto. En 1661, Jacinto Arias de Quintanadueñas afirmaba lo siguiente:

"En vna historia manuscripta antigua, que escriuió Pedro Barrantes Maldonado, Cauallero de esta Villa, intitulada Coronica de España, que he visto. En el tratado tercero haze mencion de este caso de Pelayo, como se ha referido (...). Concluye assi: Y yo Pedro Barrantes Maldonado la vi en esta villa de Alcantara, en el sacro, y notable Conuento de S. Benito, donde está aconpañada de muchas reliquias, y tenida en mucha veneracion,

\footnotetext{
53 Recientemente transcritas a partir de la copia de Fabián Antonio de la Cabrera en MarTín et al., Noticias de Alcántara, t. 1, pp. 195-304.

54 “(...) una coronica que llamo la Yllustracion de la casa de Niebla y sucession de los Guzmanes desde sus principios", Cabrera, Noticias de los papeles de don Pedro Barrantes Maldonado, f. 60r.

55 “(...) y otras provincias del mundo desde el día que el nacio que fue 1510”, CABrera, Noticias de los papeles de don Pedro Barrantes Maldonado, f. 60r.

56 Aparece específicamente en CAÑas y TEJEIRo (eds.), Catálogo bibliográfico de estritores extremeños anteriores a 1750 , t. 1, p. 252.

57 Cabrera, Noticias de los papeles de don Pedro Barrantes Maldonado, f. 60r.

58 Recoge la información Gayangos en Barrantes, Ilustraciones, t. 9, p. VI y t. 10, p. 483. Véase también Martín et al., Noticias de Alcántara, t. 1, pp. 38 y 40.

59 Díaz y Pérez, Diccionario histórico, t. 1, p. 79.

60 Catalán, La tradición manuscrita de la Crónica de Alfonso XI, pp. 34-35, nota 51.
} 
y tambien la bolui à ver en el mismo Conuento quarenta años despues de escrito este libro"

Qué manuscrito consultó Jacinto Arias no podemos saberlo a día de hoy, aunque la descripción que hace de esta crónica general no parece adecuarse a La Maldonada. En efecto, se refiere a un texto en cuyo "tratado tercero" se habla de Pelayo, mientras que los registros sobre La Maldonada, y aun la descripción de Barrantes, como hemos visto, nos hablan de un relato que abarcaba desde Alfonso X hasta la toma de Granada. ¿Acaso compiló Barrantes más de una crónica general? Es una opción que debemos considerar, sobre todo si tenemos en cuenta lo prolijo de su producción ${ }^{62}$.

A estas obras, contemos o no La Maldonada y la Corónica de España a la que alude Arias como creaciones independientes, todavía habría que sumar otro texto mencionado en sus memorias que no se recoge en los listados al uso ${ }^{63}$. A él se refiere como "un libro de mas de trezientas hojas que lo llama ytinerario de la jornada de Ungria que trata de cosas de Francia, Flandes, Alemaña y Ungria"64. Posiblemente estaban destinados a este texto los materiales que pidió a su pariente Bernardo Aldana mediante sus cartas, y que le llegaron a través de Juan Villela de Aldana ${ }^{65}$.

Además, menciona Barrantes "otro libro que lo llamo Discursso de los condes de Flandes, duques de Borgoña y Archiduques de Austria sacado de muchas coronicas francessas, alemanas y ungaras"66, que quizás podamos identificar con la denominada Historia de los condes de Flandes ${ }^{67}$. Ésta debía tener una segunda parte dedicada a Carlos V no conservada ${ }^{68}$.

${ }_{61}$ Arias, De las Antiguedades y Santos de Alcántara, Libro Segundo, p. 101. El subrayado es mío.

${ }_{62}$ El comentario que Jacinto Arias transcribe acerca de haber vuelto a ver la reliquia cuarenta años después parece propio de Barrantes Maldonado, y quizás de un manuscrito autógrafo. De hecho, resulta similar al que dejó anotado en el margen de las Ilustraciones que editó Gayangos: "Despues de muchos años aver yo escrito esta historia, mi hijo mayor y mayorazgo de mi casa Alvaro Barrantes Maldonado dexó el estudio de Salamanca", Barrantes, Ilustraciones, t. 9, p. 3 y nota 1. Gayangos afirma que el texto que edita es una copia "original y autógrafa (...). Es el borrador mismo, concluido á $1^{\circ}$ de Setiembre de 1541, como lo manifiestan, además de la firma de su autor, varias correcciones y adiciones posteriormente hechas por él, y de las cuales la última lleva la fecha de 1573", Barrantes, Ilustraciones, t. 9, p. III.

${ }_{63}$ Sí aparece referenciado en CARABIAS, "Pedro Barrantes Maldonado", p. 215.

${ }_{64}$ Cabrera, Noticias de los papeles de don Pedro Barrantes Maldonado, f. 60r.

65 Pedro Barrantes había solicitado a Bernardo de Aldana que le escribiese un "itinerario" de Hungría y un "compendio de las cosas de Alemania". Bernardo, por su parte, decía tener "entre sus papeles el discurso de las principales guerras en que yo me he hallado", pero lo cierto es que los materiales solicitados por Barrantes le llegaron de parte de Juan Villela de Aldana, hermano del anterior. Éste le enviaba una recopilación y suma de los hechos de Bernardo, de lo cual le informaría mejor en persona con lo que había ido "recogiendo en algunos cartapacios y papeles lo que yo he entendido y visto", Barrantes, Ilustraciones, t. 10, pp. 494 y 497 y ss.

66 Cabrera, Noticias de los papeles de don Pedro Barrantes Maldonado, f. 60r.

67 Con este título aparece en el MSS/6550 de la Biblioteca Nacional de España, f. IIr, donde además se indica el año de 1566.

68 MarTín et al., Noticias de Alcántara, t. 1, pp. 39-40 y p. 97. 


\section{1. ¿Cuándo compiló Barrantes su Crónica de Fernando Quarto?}

Como se observa, Barrantes Maldonado sin duda encarnó bien la conjunción de las armas y las letras a la que, como hombre de su tiempo, a veces gustaba referirse ${ }^{69}, \mathrm{y}$ cuya fama (en el decir renacentista) dejó reflejada en la posteridad ${ }^{70}$. En el marco de esta ingente producción debe integrarse su desconocida Crónica de Fernando Quarto, sobre la cual es necesario preguntarse acerca del momento y circunstancias en las que fue compilada por el historiador de Alcántara. Afortunadamente, el texto es prolijo en datos internos que permiten establecer una cronología más o menos ajustada: la crónica debió elaborarse entre el último cuarto de 1544 y finales de 1546. En el folio 20r Barrantes dice lo siguiente:

"puesto que en las coronicas de Hespaña no dize por que raçon fue en pecado [Sancho IV], yo me acuerdo aver leydo en la çiudad de Paris en la recamara del rey de Françia don Françisco que hoy hes vna coronica del rey Felipe quarto hijo del rey san Luis que dize".

Este fragmento nos sitúa en el reinado de Francisco de Francia, aunque no nos dice a cuál de los reyes que tuvieron este nombre se refiere. El primero de ellos reinó entre 1515 y 1547 , mientras que el segundo lo hizo brevemente entre 1559 y 1560. Sabemos que Barrantes viajó a Francia en 1532, por lo que sin duda debe referirse al primero de ellos ${ }^{71}$. Esto se confirma por un comentario posterior: el texto avanza refiriéndose a la lengua francesa de su fuente, y en relación a ella nos dice que "espeçialmente agora que en la casa del enperador don Carlos nuestro señor se abla tan comunmente como la lengua hespañola"72. Esta observación del historiador nos da un nuevo dato para afinar en la búsqueda del año de producción del texto: Carlos V solo coincidió como emperador con el reinado de Francisco I, lo que incide en la primera deducción. Por lo tanto, por el momento, tenemos un arco cronológico para el texto que va de 1532 a 1547 . Por otra parte, sabemos que Barrantes utilizó el texto de las Ilustraciones como una de sus fuentes, lo cual permitiría atrasar todavía más el término post quem, concretamente hasta $1541^{73}$. No obstante, la posibilidad de que lo que emplease fuesen materiales de trabajo comunes y no directamente el texto terminado podría poner en cuestión esta deducción. Pero hay otros datos que permiten afinar el arco temporal. Refiriéndose a Beltrán de la Cueva, tercer duque de Alburquerque, Barrantes escribe lo siguiente:

\footnotetext{
69 Barrantes, Ilustraciones, t. 9, p. 4.

70 Barrantes, Ilustraciones, t. 9, p. VIII; Cabrera, Noticias de los papeles de don Pedro Barrantes Maldonado, f. 76r; Martín et al., Noticias de Alcántara, t. 1, p. 58.

71 En las memorias que transcribe Fabián Antonio de la Cabrera dice que estuvo "dos veces y en diversos tiempos y años en la corte de Fransia, la primera en la siudad de Ambuessa y la segunda en la siudad de Paris", CABrera, Noticias de los papeles de don Pedro Barrantes Maldonado, f. 60r.

72 II/2457, f. 20v.

73 BARRAntes, Ilustraciones, t. 9, p. 245.
} 
"que oy bibe y a estado en Ytalia con el emperador don Carlos rey de España y en Alemaña le ayudo a conquistar los estados del duque de Gueldres Gleves y Jullieres y pasando en Yngalaterra sic ¿? Enrrique a conquistar el reyno de Françia donde está agora aviendole tomado la çiudad de Boloña"74.

La ciudad que Beltrán de la Cueva asedió con el ejército inglés de Enrique VIII fue la francesa Boulogne, cuya capitulación se produjo el 18 de septiembre de 1544, y que se mantuvo bajo dominio inglés hasta el tratado firmado en $1550^{75}$. Con ello podemos volver a atrasar el término post quem del texto, esta vez al último cuarto de 1544. Además, Enrique VIII no murió hasta enero de 1547, por lo que igualmente podemos adelantar el término ante quem del texto a finales de 1546. En definitiva, como se dijo al principio, la Crónica de Fernando Quarto de Barrantes fue compilada en algún momento entre finales de 1544 y finales de 1546.

El interés de Barrantes Maldonado por historiar el reinado de un monarca castellano no resulta aislado. Ya mencioné que en el prólogo al texto de las Ilustraciones afirmaba haberse ocupado de escribir sobre los linajes y hechos de algunos reyes y príncipes españoles y extranjeros ${ }^{76}$. Y de hecho, estando en Sanlúcar de Barrameda se ocupó del reinado de Enrique III utilizando como fuente el texto de Pedro López de Ayala ${ }^{77}$. Lo que sí ha sido diferente es la suerte de ambas crónicas reales. Por un lado, contrasta el número de copias manuscritas en la que aquélla se conserva frente al testimonio único que hoy conocemos de la de Fernando $\mathrm{IV}^{78}$. Por otro lado, aparece aquélla referenciada en todos los trabajos mencionados, en los que, como se constató, la del Emplazado se encontraba siempre ausente.

Podría pensarse que los textos de reinados que conocemos del autor, esto es, las crónicas de Fernando IV y de Enrique III, tuviesen algún tipo de relación con La Maldonada, aunque no tenemos datos para poder afirmar nada claro en este sentido. Ni siquiera sabemos si esta Maldonada funcionaría más bien como una suma de crónicas o como un

\footnotetext{
4 II/2457, f. 5v.

75 Para la descripción de los acontecimientos referentes al sitio de Boulogne véase ErLANGER, Enrique VIII, pp. 184-189. También Sandoval, Historia de la vida y hechos del Emperador Carlos V, Libro 26, 1544.

76 "Despues de aver escrito algunos libros de diversas cosas, quise ocuparme en escrevir de los linages y hechos de algunos Reyes y principes, ansi naturales como estrangeros, y acabadas las cosas de los Reyes de Hespaña y cosas notables della, escrevi de los Emperadores de Alemania y de algunos principes della", BARrantes, Ilustraciones, t. 9, p. 3.

77 El colofón de la crónica dice que lo acabó de recopilar en Sanlúcar el 4 de julio de 1541 (Real Academia de la Historia, Colección San Román, 2/Ms.42, f. 38r), apenas unos meses antes de concluir su obra sobre los Guzmanes, Barrantes, Ilustraciones, t. 9, p. III. Sobre el interés de Barrantes Maldonado en el reinado de Enrique III véase CARriazo, La casa de Arcos entre Sevilla y la frontera de Granada, p. 64. 78 Sólo en la Biblioteca Nacional de España tenemos siete copias. Del siglo XVI son las que contienen los manuscritos MSS/1663 y MSS/6119, y posteriores pueden encontrarse en MSS/1357, MSS/6915 (a partir del f. 99r), MSS/7081; MSS/13313, MSS/18024 (está catalogada como "Escritos de los sucesos históricos sobre los siglos XV y XVI", pero contiene una crónica de Enrique III en los ff. 1r-67r). A ellas podríamos sumar el manuscrito ya mencionado de la Real Academia de la Historia, Colección San Román, 2/Ms.42.
} 
texto extenso mucho más enciclopédico donde se tratase de forma prolija cada reinado. Por otra parte, se han visto ya las dificultades para saber si Barrantes elaboró más de una obra relacionada con la historia general de España, dadas las divergencias que se encontraban en las referencias aludidas con anterioridad.

Desde luego, la idea de La Maldonada contenida en un único volumen listo para la imprenta nos aleja de pensar que estas crónicas reales fuesen parte de ella. Por su extensión, también resulta difícil pensar en que fuesen parte de esa Corónica de España que abarcaba al menos desde Pelayo. Quizás le sirvieron de fuente, pues como veremos después, este trasvase de informaciones era común en el modo de trabajar del autor. De lo que no cabe duda es del enorme interés que Barrantes tuvo por la historia de España, que manifestó en el cultivo de ambos géneros, el de la crónica general y el de la crónica real.

\section{La Crónica de Fernando Quarto de Barrantes Maldonado y la relación con su homónima medieval}

El texto que dedica al reinado de Fernando IV de Castilla responde perfectamente a la variada realidad de obras que Barrantes leyó y compuso, y al amplio conocimiento que debió alcanzar sobre la historia española y extranjera. A lo largo del relato el historiador entrelaza la fuente medieval con otras fuentes de naturaleza diversa y aporta numerosos comentarios sobre sucesos ocurridos fuera de la Península Ibérica. Analizar las fuentes empleadas por el autor, así como los mecanismos de trabajo que pone en funcionamiento, será por motivos de extensión objeto de un trabajo monográfico, pero resulta pertinente aportar aquí una comprensión general de la vinculación del texto con su principal fuente, la Crónica de Fernando IV que el rey castellano Alfonso XI ordenó a mediados del siglo XIV ${ }^{79}$.

Sin duda, la crónica del siglo XIV es armadura fundamental del texto de Barrantes; sin embargo, también emplea abundantemente su obra ya aludida titulada Ilustraciones de la Casa de Niebla, muy especialmente el tramo que cronológicamente coincide con el reinado del Emplazado. Esto es, el que abarca los periodos dedicados a Alfonso Pérez de Guzmán y a su hijo y sucesor, Juan Alfonso de Guzmán. Hay que tener en cuenta que la crónica medieval fue también fuente esencial de esta obra, por lo que a veces cabe la duda de si su texto se emplea de manera directa o indirectamente, y siempre existe la posibilidad de que el historiador dispusiese de materiales intermedios que usase en ambas indistintamente. De cualquier modo, en su crónica sobre Fernando IV aparecen elementos y pasajes muy literales del texto medieval que no se encuentran en las Ilustraciones, por lo que parece claro que Barrantes utilizó ésta independientemente. Así, por ejemplo, en el capítulo 26 se intercalan ambas fuentes a criterio del autor ${ }^{80}$. El texto de Barrantes, como la fuente medieval, relatan el levantamiento popular que se

79 Como parte de la Crónica de tres reyes, Benítez, "Piezas liminares de la historiografía postalfonsí". 80 II/2457, ff. 50r-53r, en CFIV, § XVI.76-94; en Barrantes, Ilustraciones, t. 9, pp. 250-255. 
produjo en Córdoba ${ }^{81}$, que sin embargo no aparece en las Ilustraciones ${ }^{82}$. Y al contrario, en la historia de los Guzmanes se relata en este contexto la visita del rey a María Coronel $^{83}$, que no se incorpora en su crónica sobre Fernando IV, ni aparece en la del siglo XIV. Poco antes de este punto se había relatado la muerte de Alfonso Pérez de Guzmán siguiendo las Ilustraciones, y ahí el autor declaraba:

"Y quien quisiese ver particularmente los memorables hechos deste don Alonso Perez de Guzman lea las Yllustraziones de la casa de Niebla y linaxe de los Guzmanes que yo hize y alli vera los hechos del y de sus antezesores y suzesores" ${ }^{\prime 4}$.

Otro caso lo encontramos en el capítulo 22, en el que como se observará, Barrantes abre el quinceno año de reinado alejándose de la fuente medieval ${ }^{85}$. El rey y la reina se han reunido con diversos representantes del reino para tratar la problemática económica. El objetivo era incrementar los ingresos para hacer frente a los gastos que asfixiaban a la corona. La crónica de Barrantes sigue muy de cerca la fuente medieval, a la que añade comentarios propios; sin embargo, las Ilustraciones, que tienden a ser, como digo, la fuente principal en las últimas partes del texto, presentan esta cuestión de manera muy sumaria $^{86}$.

Tal y como ocurre en estos casos, una comparativa general entre ambas permite rastrear la presencia de la crónica medieval sin problema a lo largo de toda la narración, pero también el distanciamiento que en ocasiones lleva a cabo con respecto a ella, haciendo de este texto una obra nueva. En efecto, esos cambios van más allá de la incorporación de las Ilustraciones como fuente de preferencia en algunos tramos del relato. Desde el punto de vista interno, el autor introduce también otras fuentes de información cuyos contenidos se amalgaman a través de diversos mecanismos de resumen, amplificación y reestructuración, y que, como adelantaba, serán motivo de un trabajo monográfico. Desde el punto de vista externo, se observan también divergencias estructurales en la organización de capítulos, así como en la ordenación cronológica del texto. Veámoslo. A diferencia de la crónica medieval, el texto de Barrantes se estructura en 27 capítulos, al menos si atendemos a la numeración de sus epígrafes. Sin embargo, la cuestión es algo más compleja. Hay segmentaciones que no deben interpretarse como parte de la armadura estructural de capítulos, puesto que no son vistas -ni numeradas- como tales por el autor. Por ejemplo, existe un caso en el que se incorpora un salto de párrafo y un

\footnotetext{
II/2457, f. 50v, en CFIV, § XVI.77.

Debería encontrarse en BARrantes, Ilustraciones, t. 9, p. 251.

83 En el contexto de las bodas de doña Isabel, hermana de Fernando IV, con el Duque de Bretaña, en BARrantes, Ilustraciones, t. 9, p. 252.

$84 \mathrm{II} / 2457$, f. $48 \mathrm{v}$.

85 El inicio de capítulo introducido por Barrantes en II/2457, f. $43 \mathrm{v}$.

86 Compárese Barrantes, Ilustraciones, t. 9, p. 233; CFIV, §XVI.54 y II/2457, f. 43v.
} 
epígrafe, pero no lleva el ordinal en cuestión precedido del término "capítulo"87. Por otra parte, el autor introduce varios años de reinado con saltos de línea y un calderón marginal sin incorporarlos tampoco en la armadura de capítulos (no tienen epígrafe ni ordinal), a pesar de que llevan la cronología introductoria propia de la fuente medieval al comenzar un capítulo. Así, la estructura externa de la crónica de Barrantes sería la siguiente:

TABLA 1.

Estructura externa de la Crónica de Fernando IV de Barrantes Maldonado

\begin{tabular}{|c|c|c|c|l|}
\hline \multicolumn{2}{|c|}{ Capítulo } & II/2457 & $\begin{array}{c}\text { Contenido } \\
\text { del inicio } \\
\text { en CFIV }\end{array}$ & \\
\hline 1 & primero & $1 \mathrm{r}$ & $\S$ I.1 & $\begin{array}{l}\text { Primer año de reinado, abril de 1295. Incorpora una } \\
\text { amplia enumeración de cronologías y los gobernantes } \\
\text { contemporáneos de diversas potencias europeas (Papado, } \\
\text { Imperio -informando de la disputa entre Luis de Baviera } \\
\text { y Federico de Austria-, Francia, Inglaterra, Aragón, Portu- } \\
\text { gal, Navarra, Granada, Turcos) }\end{array}$ \\
\hline $\mathbf{2}$ & segundo
\end{tabular}

87 Así ocurre en II/2457, f. 17r.

88 Este tipo de cronologías se observa también en otras obras del autor, ver, por ejemplo, BaRRANTES, Ilustraciones, t. 9, p. 248. Los contactos entre ésta y la crónica aquí analizada se tratarán con mayor detenimiento más adelante. 


\begin{tabular}{|c|c|c|c|c|}
\hline 14 & catorze & $27 \mathrm{r}$ & $\S \mathrm{XII} .1$ & Décimo año de reinado, 1304. \\
\hline 15 & $X V$ & $29 \mathrm{r}$ & $\S \mathrm{XII} .2$ & \\
\hline 16 & $\begin{array}{l}\text { diez } y \\
\text { seis }\end{array}$ & $30 \mathrm{v}$ & $\S$ XII.17 & \\
\hline 17 & $\begin{array}{l}\text { XVII diez } \\
y \text { siete }\end{array}$ & $32 \mathrm{r}$ & $\S$ XIII.1 & Onceno año de reinado, 1305. \\
\hline 18 & $\begin{array}{c}\text { XVIII } \\
\text { diez y } \\
\text { ocho }\end{array}$ & $34 \mathrm{r}$ & $\S$ XIV.1 & $\begin{array}{l}\text { Doceno año de reinado, } 1306 \text {. En el f.35v introduce el } \\
\text { treceno año de reinado, año de } 1307 \text {, que corresponde a } \\
C F I V \text { a } \S \text { XV.1. }\end{array}$ \\
\hline 19 & $\begin{array}{l}\text { XIX diez } \\
y \text { nueve }\end{array}$ & $37 v$ & $\S$ XVI.1 & Catorceno año de reinado, 1308 \\
\hline 20 & $\begin{array}{c}\text { XX veyn- } \\
\text { te }\end{array}$ & $39 \mathrm{r}$ & $\S \mathrm{XVI} .18$ & \\
\hline 21 & $X X I$ & $41 \mathrm{v}$ & $\S \mathrm{XVI} .24$ & \\
\hline 22 & $X X I I$ & $43 r$ & $\S$ XVI.53 & $\begin{array}{l}\text { Quinceno año del reinado, } 1309 \text {. Téngase en cuenta que la } \\
C F I V \text { no introduce el quinceno año hasta } \S \text { XVII.1. }\end{array}$ \\
\hline 23 & $X X I I I$ & $45 \mathrm{r}$ & $\S \mathrm{XVI} .61$ & \\
\hline 24 & XXIIII & $46 r$ & --- & $\begin{array}{l}\text { No hay correspondencia con } C F I V \text { ya que la fuente prin- } \\
\text { cipal es el texto de las Ilustraciones, donde también se } \\
\text { observa esta división de capítulo, t. 9, p. } 237 \text {. El capítulo } \\
\text { anterior acaba, eso sí, en } \S \text { XVI.68. }\end{array}$ \\
\hline 25 & $X X V$ & $48 \mathrm{r}$ & --- & $\begin{array}{l}\text { Todavía la fuente principal son las Ilustraciones, t. 9, p. } \\
\text { 240, aunque la división de capítulo es propia de este texto } \\
\text { de Barrantes. }\end{array}$ \\
\hline 26 & $X X V I$ & $50 \mathrm{r}$ & $\S$ XVI.76 & \\
\hline 27 & $X X V I I$ & $53 r$ & $\S$ XVII.1 & $\begin{array}{l}\text { Suprime la cronología referente al quinceno año de reina- } \\
\text { do que aparece en } C F I V \text {, } \S \text { XVII.1 ya que ha optado por } \\
\text { iniciarlo en el capítulo XXII de su texto. }\end{array}$ \\
\hline
\end{tabular}

Como se observa en la tabla, la estructura externa del texto de Barrantes Maldonado se separa en numerosas ocasiones de su fuente: aunque marca todos los años de reinado hasta 1309, no siempre los hace equivaler con un nuevo capítulo, lo cual rompe la estructura analística propia de la crónica medieval. Por otra parte, un amplio segmento que coincide con los capítulos 24 y 25 está más vinculado a las Ilustraciones que a la fuente medieval, incidiendo en esa divergencia estructural.

El texto se aleja igualmente de la crónica medieval en la información cronológica, al respecto de lo cual aporta el año de reinado, el mes y el año del señor, pero suprime la era de César que es común en su fuente. En relación a la cronología, llama la atención que el autor no corrija el desfase cronológico que acarrea la fuente y que se observa desde el cuarto año de reinado, dentro del capítulo 7, ello a pesar de que al final de su texto constata 
la fecha errónea del nacimiento de Alfonso XI ${ }^{89}$. Quizás la problemática cronológica sea precisamente el motivo por el que deja de marcar los años de reinado a partir de 1309 .

En este sentido, conviene también subrayar la incorporación del quinceno año de reinado en el capítulo 22, que corresponde en el texto medieval a $\S$ XVI.53. Supone cierto intento de mejorar el problemático capítulo XVI de la fuente, que aglutina varios años de reinado, concretamente de 1307 a 1311, en el que considera erróneamente el catorceno año de reinado, fechado por ella en 1308. De cualquier modo, ambos relatos son cronológicamente erróneos, pues Barrantes localiza el inicio del año quinceno en un punto en el que la historia real sigue situándonos en 1308. Por su parte, el texto medieval abre este año ya en $\S$ XVII.1, lo cual nos lleva a 1311. Así, ambas coinciden en el error de situar la estancia del rey en Burgos (para lo que Barrantes llama Cortes y el texto medieval ayuntamiento) en 1309 y no en $1308^{90}$.

Quisiera detenerme en un último aspecto: qué relación tiene el texto de Barrantes específicamente con los manuscritos que conservamos de la crónica medieval y no con su texto en abstracto. A lo largo de sus trabajos sobre la Gran crónica de Alfonso XI, Diego Catalán se ocupó de su utilización como fuente para las Ilustraciones de la casa de Niebla ${ }^{91}$. En relación a esto, planteaba Catalán el uso por parte del extremeño de un manuscrito hermano al que hoy se conserva en la Biblioteca Menéndez Pelayo de Santander con signatura M-563 (en adelante $C)^{92}$.

El investigador afirmaba desconocer aún el uso de la Gran Crónica por Barrantes en 1955. En 1959 proponía que "aprovechó en amplia medida, a veces hasta textualmente, un ms. de la Gran Crónica de Alfonso XI que se hallaba en la biblioteca de la casa de Niebla en la villa de Sanlúcar"93, mientras que se refería ya específicamente al manuscrito $C$ en años posteriores ${ }^{94}$. Lo que no podemos saber es si ambas consideraciones de Catalán deben identificarse con el mismo manuscrito, pues desconocemos los datos de procedencia de $C$, salvo que estuvo en Madrid ${ }^{95}$. Se trata éste, sin duda, de uno de los

\footnotetext{
$89 \mathrm{II} / 2457$, f. 50 r.

90 II/2457, f. 43v; CFIV, § XVI.53. Sobre los problemas de la estructura cronológica de la Crónica de Fernando $I V$ y su posible relación con el proceso de producción del texto remito a Benítez, "Tras los pasos del rey".

91 Catalán, Gran Crónica de Alfonso XI, t. 1, pp. 77-85.

92 Seguiré las siglas empleadas en Benítez, Crónica de Fernando IV. Para una tabla de los manuscritos que transmiten la Crónica de Fernando $I V$, sus signaturas y las siglas empleadas por distintos investigadores véase pp. LXXIV-LXXV. Diego Catalán identifica este manuscrito con la sigla $S$, CATALÁN, La tradición manuscrita de la Crónica de Alfonso XI, pp. 394-395; CATAlán, Gran Crónica de Alfonso XI, t. 1, p. 266. En ocasiones lo cita como 317 por la numeración con la que aparece en ArTigas y SÁNCHEZ, Catálogos de la Biblioteca de Menéndez Pelayo, p. 411.

93 Catalán, "Las estrofas mutiladas en el ms. E del Poema de Alfonso XI", p. 328, nota 10.

94 Catalán, "La Estoria del fecho de los godos", p. 249, nota 93.

95 Rodgers, Prolegomena to a critital edition, p. 201.
} 
manuscritos más antiguos y singulares de la tradición manuscrita de la Crónica de tres reyes $^{96}$, y de la sección -independiente con respecto a la anterior- sobre Alfonso XI ${ }^{97}$.

La relación de Barrantes con este manuscrito o uno hermano a él resulta clara también en el caso que nos ocupa. Esto es así, en primer lugar, por la presencia dentro del texto de su crónica de dos pasajes ausentes en la amplia tradición manuscrita de la Crónica de Fernando $I V$ y que sin embargo aparecen en $C^{98}$. El primero se refiere al diálogo mantenido entre Dionís de Portugal y Juan Núñez de Lara tras la actitud soberbia de aquél a su entrada en Castilla para asediar al rey Fernando ${ }^{99}$. El segundo se refiere a cómo Juan Alfonso de Haro "acreçentó" su escudo con "vn carnero o obeja” colocado en la boca de cada uno de los lobos que ya llevaba después de su victoria contra Juan Núñez de Lara ${ }^{100}$.

Hay otros aspectos que pueden apoyar la cercanía entre $C$ y la crónica de Barrantes. Antes de proceder a dar algunos ejemplos conviene resaltar que algunos aparecen también en otros testimonios que tienen una relación con $C$ dentro del estema ${ }^{101}$. A pesar de ello, parece claro que el texto de Barrantes se vincula con $C$ o un manuscrito hermano hoy perdido, y no con esos otros testimonios. En efecto, la crónica de Barrantes concentra una serie de características que aparecen en conjunto en $C$, mientras que sólo parcialmente en esos otros manuscritos, y siempre por su relación con éste. Por otra parte, insisto en que sólo $C$ y Barrantes contienen los dos episodios aludidos.

Desde el punto de vista externo, coinciden en la apertura del segundo capítulo, que Barrantes situaba en el folio $2 \mathrm{v}$ y que se establece después de $\S \mathrm{I} .11^{102}$. También presentan capitulación común tras $\S$ I.22, que Barrantes sitúa en el folio 7r. Pero la capitulación por sí sola resulta poco determinante a la hora de establecer relaciones entre testimonios

\footnotetext{
96 Para mayor información sobre el manuscrito véase SARAcino, Crónica de Sancho IV, pp. CXXXIX-CXL; Benítez, Crónica de Fernando IV, pp. LXXXVIII-LXXXIX y CXXV-CXLIII; Rodgers, Prolegomena to a critital edition, pp. 201-211; CATALÁn, La tradición manuscrita de la Crónica de Alfonso XI, pp. 394-395; Faulhaber et al., Philobiblon, BETA manid 1247.

97 Catalán, La tradición manuscrita de la Crónica de Alfonso XI, p. 241, nota 66.

98 Benítez, Crónica de Fernando IV, pp. CXXXIX-CXLIII; los pasajes en p. 35, nota 45 y p. 58, nota 94.

99 II/2457, f. 12r. No se encuentra en BARRANTES, Ilustraciones, ver t. 9, pp. 184-185.

100 II/2457, f. 19r. Desde luego, estas disquisiciones sobre el origen de los escudos son muy del gusto de Barrantes, como puede observarse en otros casos. Algunos ejemplos en BARRANTEs, Ilustraciones, t. 9, pp. 21, 23-24 (citando el Libro de linages y armas de los nobles de España de Gracia Dei), 69, 89, 179, 210-211, $219,327,418,461$. No aparece sin embargo el caso que aquí se comenta, y tampoco la información sobre el origen del escudo en Gracia Dei, fuente usual de Barrantes, ver Gracia Dei, Nobiliario, MSS/18053, f. $19 \mathrm{v}$.

101 Se trata, por un lado, de los manuscritos B1498 de la Hispanic Society de Nueva York y M-II-2 del Escorial, en adelante $E$ y $F$ respectivamente. En lo que afecta a la Crónica de Fernando $I V$ estos testimonios y $C$ aparecen paralelos hasta entrado el segundo año de reinado, concretamente en $C F I V$, $\S$ II.7. Para más información sobre la posible relación de estos testimonios véase Benítez, Crónica de Fernando IV, pp. CXVI-CXXV y CLI-XLII. Por otro, los manuscritos Y-I-5 del Escorial y MSS/10132 de la Biblioteca Nacional de España (en adelante $A$ y $B$ respectivamente). Sobre estos testimonios y su relación con $C$ remito de nuevo a Benítez, Crónica de Fernando IV, pp. CXXV-CXXXVII.

${ }^{102}$ La división de capítulo coincide, pero Barrantes suprime el texto de $C F I V, \S$ I.12-13.
} 
si no se acompaña de otros elementos, máxime cuando se ha observado que los criterios organizativos de Barrantes son diferentes a los del texto medieval, y que a veces su fuente básica es el texto de las Ilustraciones.

Más sólidos resultan los elementos internos a la hora de establecer la cercanía entre los testimonios. Es el caso de la reestructuración de contenidos que realizan en $\S$ I.9.5-9, que también se observa en Barrantes ${ }^{103} \mathrm{o}$, especialmente, de las lecturas comunes. Por ejemplo, Barrantes afirma que Sancho IV tomó de su madre doña Violante "las villas de Valladolid de Palençuela Astudillo Nuño Curiel Santisteuan de Gormaz Vexar y otros pueblos"104. El texto medieval indica que se trata de las villas de "Plasençia e Ayllon e Estudillo" 105 , mientras que $C$ lee, coincidiendo con Barrantes, "de Palençuela e de Astudillo e de Nunno"106.

Podemos poner otros ejemplos, como la especificación que Barrantes hace sobre Juan Núñez de Lara, "que llamavan de la barva" y que se encuentra asimismo en $C$, "que dezian de la barua"107. O igualmente comparten la localización del inicio del año de reinado de 1303 en enero y no en abril. Este error aparece también en $A$ y $B$, pero en $C$ presenta además un cambio de orden que coincide también con el texto de Barrantes: ambos sitúan en este caso el mes al final de las cronologías, y no al comienzo ${ }^{108}$. Por otra parte, Barrantes introduce los años de reinado con la fórmula el "año del señor", en lo que coincide también con $C^{109}$.

Hay otra cuestión que es necesario subrayar. El manuscrito $C$ corta bruscamente su copia de la Crónica de Fernando $I V$ antes de llegar al final, concretamente en el año noveno de reinado ${ }^{110}$. A partir de este punto resulta imposible por lo tanto seguir comparando el texto, aunque sabemos por Diego Catalán que también utilizó Barrantes la copia sobre Alfonso XI que viene a continuación dentro del manuscrito ${ }^{111}$.

Más adelante el texto de Barrantes sigue mostrando relación con $E$, que como habíamos visto se encontraba cercano a $C$ en el primer tramo de texto, y que de cualquier modo sigue estando después en la misma rama de la tradición. Un ejemplo lo encontramos al referirse a las vistas que Fernando IV había concertado con Jaime II para concluir el problema con Alfonso de la Cerda. El texto de Barrantes las sitúa en Huerta de

\footnotetext{
${ }^{103} \mathrm{II} / 2457$, f. $2 \mathrm{v}$.

104 II/ 2457 , f. 8 r.

${ }^{105}$ CFIV, § I.40.3-4.
}

106 Benítez, Crónica de Fernando IV, Edición (cd-rom), § I.40.3-4. La misma lectura presenta $F$, mientras que $E$ lee "e Palençia e Munno e Astudillo". Para más información sobre ésta y otras lecturas comunes entre estos manuscritos véase Benítez, Crónica de Fernando IV, p. CXVII.

107 II/2457, f. 18v; Benítez, Crónica de Fernando IV, Edición (cd-rom), § VII.1.

${ }^{108}$ II/2457, f. 25v. Con respecto a $A, B$, y $C$ véase el aparato crítico en Benitez, Crónica de Fernando IV, Edición (cd-rom), § XI.1.R-N.

${ }_{109}$ Compárese II/2457, f. 13v y aparato crítico en Benítez, Crónica de Fernando IV, Edición (cd-rom), $\S$ III.1.N, por poner solo un ejemplo. La tradición manuscrita de la crónica medieval suele leer "año del nacimiento".

110 Benítez, Crónica de Fernando IV, p. LXXXIX.

111 Catalán, "La Estoria del fecho de los godos", p. 249, nota 93. 
Haryza $^{112}$, que $E$ lee como Huerta de Harza y el resto de la tradición como Huerta de San Andrés ${ }^{113}$. Es de notar que también aparece Huerta de Hariza en las Ilustraciones de la casa de Niebla ${ }^{114}$.

Llegados a este punto resulta necesario recoger algunas ideas: el testimonio de la Crónica de Fernando Quarto de Barrantes parece confirmar la cercanía de su autor al testimonio $C$ o alguno cercano a él, como ya propuso Diego Catalán para el texto de las Ilustraciones. No obstante, la ausencia de este testimonio en un fragmento muy amplio del relato, pues como se ha indicado, finaliza su copia en el noveno año de reinado, complica la filiación del texto en los tramos posteriores. Esto es así debido a la contaminación que encontramos dentro de la tradición manuscrita de la Crónica de Fernando $I V$ y a las complicaciones que presenta en los últimos años de reinado, donde además tiene contactos con la tradición de la Crónica de Alfonso $X I^{115}$. Por otra parte, el segmento final de la crónica de Barrantes se encuentra profundamente resumido con respecto a la fuente, lo que dificulta aún más la filiación.

Un dato más en ese sentido, el texto de Barrantes concluye añadiendo un recuento cronológico de la vida y reinado de Fernando IV, lo cual es propio de la rama opuesta a los manuscritos que hemos estado analizando dentro de la tradición manuscrita de la crónica medieval ${ }^{116}$. Y, sin embargo, sí que se observa la referencia al intento de deposición de Fernando IV tal y como aparece en los testimonios $E$ y $F$, como hemos visto cercanos a $C$ en algunos tramos del relato ${ }^{117}$, y que además vincula a estos testimonios con la tradición manuscrita de la Crónica de Alfonso XI en su versión vulgata ${ }^{118}$. Así, la contaminación que se observa en el último sector de la crónica de Fernando IV, que también se percibe en Barrantes, insisten en la necesidad de seguir reflexionando más profundamente, y de manera comparativa, sobre la historia textual de la crónica medieval.

\section{A modo de conclusión}

La Crónica de Fernando Quarto de Pedro Barrantes Maldonado supone una fuente de primer orden sobre un reinado que cuenta con escasos relatos historiográficos propios, más allá de la crónica ordenada por Alfonso XI a mediados del siglo XIV o el texto de Jofré de Loaysa que finaliza en $1305^{119}$. Como se ha observado, aglutina diversas fuentes de origen medieval que su autor conoció, tradujo y trabajó a lo largo

112 II/2457, f. 44v, corregido por el copista.

113 Véase el aparato crítico en Benítez, Crónica de Fernando IV, Edición (cd-rom), § XVI.58.9.

114 BarRantes, Ilustraciones, t. 9, p. 233.

115 A este respecto véase Benítez, Crónica de Fernando IV, especialmente pp. XCIII-C.

116 Esto a excepción de $B$, que pese a formar parte de la rama de manuscrito que venimos analizando, ha cambiado de modelo en su tramo final, Benítez, Crónica de Fernando IV, p. CLII.

117 CFIV, § XVIII.3; en II/2457, f. 53v. A ellos se añade el testimonio 9/4761 de la Real Academia de la Historia, todos los cuales se encuentran ligados a la Crónica de Alfonso XI en este tramo.

118 Crónica de Alfonso XI, ed. Francisco Cerdá, p. 7. Para más información sobre la relación de las crónicas de Fernando IV y Alfonso XI ver Benítez, Crónica de Fernando IV, pp. XCIII-CVI.

119 LOAYsa, Crónica de los reyes de Castilla. 
de su vida, no solo para este texto sino para una extensa producción literaria que desgraciadamente hoy se encuentra parcialmente perdida.

Por otra parte, supone una herramienta más para profundizar en el conocimiento crítico de la tradición textual del texto medieval por el uso de manuscritos sumamente interesantes, como el ya apuntado M-563 de la Biblioteca Menéndez Pelayo de Santander y otros de su misma rama. El hecho de que este testimonio interrumpa su copia bruscamente en el noveno año de reinado quizás sea indicio para pensar en un códice hermano a él que sí contase con el texto completo y que fuese el que verdaderamente empleó Barrantes Maldonado para componer su crónica. Éste supone además, junto con el códice aludido, el único testimonio de dos pasajes sobre el reinado de Fernando IV desconocidos por el resto de la tradición manuscrita del texto medieval.

En definitiva, este artículo ha pretendido realizar una presentación del manuscrito y el texto de Barrantes, ofrecer una descripción general de su contenido y plantear algunas observaciones sobre su relación con la fuente medieval y los testimonios que la transmiten. Convendrá en lo sucesivo seguir reflexionando y arrojando luz sobre él en el camino hacia una futura edición.

\section{Referencias}

Arias de Quintanadueñas, Jacinto, De las Antiguedades y Santos de Alcántara, Impresor Mateo Fernández, Madrid, 1661.

Artigas, Miguel y Sánchez, Enrique, Catálogos de la Biblioteca de Menéndez Pelayo. I. Manuscritos, Santander, Cuerpo facultativo de archiveros, bibliotecarios y arqueólogos y Sociedad de Menéndez Pelayo, Santander, 1957.

Barrantes Maldonado, Pedro, Ilustraciones de la casa de Niebla, ed. Pascual de Gayangos, Memorial Histórico Español, t. 9-10, Real Academia de la Historia, Imprenta Nacional, Madrid, 1857.

BARrantes, Vicente, Catálogo razonado y crítico de los libros, memorias y papeles, impresos y manuscritos, que tratan de las provincias de Extremadura, así tocante a su historia, religión y geografía, como a sus antigüedades, nobleza y hombres célebres, Imprenta y Estereotipia de M. Rivadeneyra, Madrid, 1865.

Benítez Guerrero, Carmen, "Manuscritos y cronistas: los problemas del trabajo en torno a la Crónica de Fernando IV de Castilla", Cahiers d'études hispaniques médiévales, 37/1 (2014), pp. 77-88.

Benítez Guerrero, Carmen, Crónica de Fernando IV: estudio y edición de un texto postalfonsí, Universidad de Sevilla, Cátedra Alfonso X el Sabio, El Puerto de Santa María, 2017.

Benítez Guerrero, Carmen, "Piezas liminares de la historiografía postalfonsí: edición y análisis del prólogo de la Crónica de tres reyes", Medieval Studies in Honour of Peter Linehan, Francisco J. Hernández, Rocío Sánchez Ameijeiras y Emma Falque, eds., SISMEL, Edizioni del Galluzzo, Florencia, 2018, pp. 345-371. 
Benítez Guerrero, Carmen, "Tras los pasos del rey: la estructura cronotopográfica de la Crónica de Fernando IV como vía de acceso a la historia del texto", Historia. Instituciones. Documentos, 46 (2019), pp. 293-325.

Briquet, Charles-Moïse, Les filigranes, dictionnaire historique des marques de papier dès leur apparition vers 1282 jusqu'en 1600, t. 3, A. Jullien, Ginebra, 1907.

Cabrera, Fabián Antonio de la, Noticias de los papeles de don Pedro Barrantes Maldonado, Madrid, Biblioteca Nacional de España, MSS/17996.

Calímaco, Callimachi Cyrenaei hymni (cum suis scholiis graecis) \& epigrammata eiusdem Poematium de coma Berenices à Catullo versum, Henricus Stephanus, Génova, 1577.

Calímaco, Himnos, epigramas y fragmentos, trads. Luis Alberto de Cuenca y Máximo Brioso Sánchez, Gredos, Barcelona, 1980.

Cancionero general recopilado por Hernando del Castillo, Real Academia Española, Madrid, 1958 (reed. de Valencia, 1511).

Cañas Murillo, José y Tejeiro Fuentes, Miguel Ángel (eds.), Catálogo bibliográfico de estritores extremeños anteriores a 1750, t. 1, Villanueva de la Serena, Diputación de Badajoz, Junta de Extremadura, 2010.

Carabias Torres, Ana María. "Turcos contra católicos. Barrantes Maldonado y la deformación interesada de los hechos militares", Tiempos Modernos, 6/19 (2009), pp. 1-30, http://www.tiemposmodernos.org/tm3/index.php/tm/article/view/177/234 [25 mayo 2019].

Carabias Torres, Ana María, "Pedro Barrantes Maldonado", Christian-Muslim Relations. A Bibliographical History: Volume 6. Western Europe (1500-1600), David Thomas y John Chesworth, eds., Brill, Leiden, 2014, pp. 215-218.

Carriazo, Juan Luis, La Casa de Arcos entre Sevilla y la frontera de Granada (13741474), Universidad de Sevilla, Fundación Focus Abengoa, Sevilla, 2003.

CArriazo, Juan Luis, "La Crónica de San Isidoro del Campo, primera historia de Guzmán el Bueno", La conciencia de los antepasados: la construcción de la memoria de la nobleza en la Baja Edad Media, Arsenio F. Dacosta, José Ramón Prieto, José Ramón Díaz de Durana, coords., Marcial Pons, Madrid, 2014, pp. 237-270.

Castro, Alfonso de, De iusta haereticorum punitione libri tres, Viuda y herederos de Juan Stelsio, Amberes, 1568 ( $1^{\mathrm{a}}$ ed. Salamanca, Imprenta de Juan de la Junta, 1547).

Catalán, Diego, "Las estrofas mutiladas en el ms. E del Poema de Alfonso XI", Nueva Revista de Filología Hispánica, 13 (1959), pp. 325-334.

Catalán, Diego, La tradición manuscrita de la Crónica de Alfonso XI, Gredos, Biblioteca Románica Hispánica, Madrid, 1974.

Catalán, Diego, Gran crónica De Alfonso XI, 2 t., Gredos, Madrid, 1977.

Catalán, Diego, "La Estoria del fecho de los godos hasta 1407 y sus continuaciones y refundiciones", La Estoria de España de Alfonso X: creación y evolución, Universidad 
Autónoma de Madrid, Fundación Menéndez Pidal, Madrid, 1992, pp. 231-285 (reed. de "El Toledano romanzado y las Estorias del fecho de los godos del siglo XV", Estudios dedicados a James Homer Herriott, Universidad de Wisconsin Press, Madison, 1966, pp. 9-102).

Córdoba de la Llave, Ricardo y Cerezo Villegas, Manuel, "Filigranas del Archivo Municipal de Córdoba (1450-1550)", Revista de Historia Medieval de la Universidad de Alicante, 6 (1988) pp. 407-434.

Crónica de D. Alfonso el Onceno de este nombre, ed. Francisco Cerdá y Rico, Imprenta de Antonio Sancha, Madrid, 1787.

Devís Márquez, Federico, "Presentación”, Ilustraciones de la Casa de Niebla, Universidad de Cádiz, Cádiz, 1998, pp. XXI-XXVI.

DíAz, José Simón, Bibliografía de la literatura hispánica, t. 6, Adiciones al t. 5-6, CSIC, Madrid, 1973.

DíAz y PÉRez, Nicolás, Diccionario histórico, biográfico, crítico y bibliográfico de autores, artistas y extremeños ilustres, 2 t., Pérez y Boix Editores, Madrid, 1884.

DuRÁn, Agustín, Romancero general o colección de romances castellanos, Rivadeneyra, Madrid, t. 1, 1849, t. 2, 1861.

Erlanger, Philipe, Enrique VIII, Salvat, Barcelona, 1986.

Faulhaber, Charles B., Gómez Moreno, Ángel y Perea Rodríguez, Óscar, dirs., BETA (Bibliografía Española de Textos Antiguos), Bancroft Library, Universidad de California, Berkeley, 1997-, http://vm136.lib.berkeley.edu/BANC/philobiblon/betaen.html [20 de mayo de 2019].

Fiorentini, Leonardo, "Lector indoctus: Callimaco e Cicerone", Annali Online di Ferrara, 8/1, (2013) pp. 33-36.

Garulli, Valentina, “Cleombroto di Ambracia e il 'lector in fabula' in Callimaco (Call. 'Epigr.' 23PF)”, Lexis, 25 (2007), pp. 325-336.

GiL, Juan, "Marcial en España”, Humanitas, 56 (2004), pp. 225-326.

IBIS. Base de datos del patrimonio bibliográfico de Patrimonio Nacional, http://realbiblioteca.patrimonio nacional.es/cgi-bin/koha/opac-main.pl [5 mayo 2019].

Loaysa, Jofré de, Crónica de los reyes de Castilla, trad. Antonio García Martínez, reed. de Alfred Morel Fatio, Academia Alfonso X el Sabio, Murcia, 1982.

Marcial, Marco Valerio, Epigramas, eds. Juan Fernández Valverde y Antonio Ramírez de Verger, Gredos, Barcelona, 1997.

Marcial, Marco Valerio, Epigramas, ed. Juan Fernández Valverde, trad. Enrique Montero Cartelle, Alma Mater, Madrid, 2004.

Martín Nieto, Dionisio Ángel, Miranda Díaz, Bartolomé, Martín Nieto, Serafín y López de Zuazo y Algar, José María, Noticias de Alcántara. Pedro Barrantes Maldonado y sis Antigüedades de la villa de Alcántara, Gráficas Romero, Diputación de Cáceres, 2 t., 2010. 
MaurA, Juan Francisco, "Pedro Barrantes Maldonado", Real Academia de la Historia, Diccionario Biográfico electrónico, http://dbe.rah.es/ [27 mayo 2019].

Nicolás Antonio, Bibliotheca Hispana sive Hispanorum scriptorum qui ab anno MD ad MDCLXXXIV floruere notitia, 2 vols., Imprenta de Joaquín de Ibarra, Madrid, 1788 $\left(1^{\mathrm{a}}\right.$ ed. 1672$)$.

Rivero, Casto María del, "Índice de las personas, lugares y cosas notables que se mencionan en las tres crónicas de los reyes de Castilla: Alfonso X, Sancho IV y Fernando IV”, Hispania. Revista Española de Historia, 9 (1942), pp. 557-618.

Rodgers, Paula Kelley, Prolegomena to a critical edition of the Cronica de Alfonso X, Ann Arbor, University Microfilms International, Michigan, 1985.

SÁnchez Alonso, Benito, Historia de la historiografía española, 2 t., CSIC, Madrid, 1941-1950.

Sandoval, Prudencio de, Historia de la vida y hechos del Emperador Carlos V, edición y estudio preliminar de Carlos Seco Serrano, Atlas, Madrid, 1955-1956.

Saracino, Pablo Enrique, Crónica de Sancho IV, Incipit, Buenos Aires, 2014.

SARAcino, Pablo Enrique, Lorenzo de Padilla: un prosista anónimo del siglo XVI, Miño Dávila Editores, Buenos Aires, 2016.

Saracino, Pablo Enrique, "Sánchez de Valladolid en el siglo XVI: la Segunda parte de las Crónicas de España de Lorenzo de Padilla (BNM 1342)", Bulletin of Hispanic Studies, 93/4 (2016), pp. 735-755, https://doi.org/10.3828/bhs.2016.46 [15 mayo 2019]. SARAcino, Pablo Enrique, "La Primera parte de las Crónicas de España de Lorenzo de Padilla: versiones y manuscritos", Revista de filología española, 98/1 (2018), pp. 217 239, https://doi.org/10.3989/rfe.2018.09 [15 mayo 2019].

Serrano y Sanz, Manuel, "III. Libros manuscritos o de mano de la Biblioteca del Conde de Gondomar", Revista de archivos, bibliotecas y museos, 8 (1903), pp. 65-68.

Vives, Luis, Quintus Tomus Operum Diui Aurelii Augustini Hipponensis episcopi, Thielman Kerver in aedibus Yolanda Bonhomme, París, 1541 ( $1^{\mathrm{a}}$ ed. 1522). 